\title{
Dwelling, Place, and Environment: Towards a Phenomenology of Person and World by David
}

Seamon and Robert Mugerauer (Eds.), Dordrecht, Netherlands: Martinus Nijhoff, 1985.

Reviewed by

David Rothenberg

University of Oslo

I have been asked to review an anthology volume on various approaches toward understanding the relationships between person and environment. They have been bound together under the common label phenomenology. This is a word I have always had trouble understanding. It seems to imply so much and so little at the same time. Each one of the authors here either states or implies a different definition of the term. It is somewhere in the region of convergence of these definitions that the reader should be able to proceed "toward a phenomenology of person and world."

The editors write in their introduction what they believe phenomenology can offer us: "It allows phenomena to be understood as they are without the reduction or distortion so often the result of positivist science or the many styles of structuralism" (p. 2). Phenomenology is supposed to let the things speak for themselves. My immediate reaction is "How?" - especially beneath so much rhetoric and unfamiliar language with such impressive hopes and pretensions. But let the book speak for itself, and I will suppress my own prejudices and ignorance. That is the phenomenological approach, I suppose. From here on I try to remove the "I" from my commentary.

As an anthology, it shouts in many voices.

Geographer Edward Relph (in his contribution "Geographical Experiences and Being-in-the-World") announces that phenomenology is a way of thinking that enables us to see what is "right before our eyes, yet somehow obscured" (p. 16) by our own thought and systems which are themselves the basic cause of our great alienation. Within the discipline of geography he argues for a shift from Yi Fu Tuan's definition of the field of study as "understanding of man-inthe-world" to a quest for "being-in-the-world"-derived somewhat from Heidegger. Relph introduces different, experienced notions of the terms region, space, and place. To move toward understanding, such terms must be lived and entered, not merely classified or described. A "thoughtful and careful" attitude to the world is needed.

But how do we develop this? Who has it? This is a difficult question and one that many of the authors tend to put off, merely suggesting 
it as a nebulous next step that we should all work toward. Perhaps this is true and is the healthy sign of a dawning discipline and field of inquiry: more questions and directions raised than answers given. In our time it is far easier to discuss the obstacles to true phenomenological understanding. These include the limitations of language, according to philosopher Robert Mugerauer (in "Language and the Emergence of Environment"). He recounts how early European explorers could only see evil in the stark forms of the Grand Canyon, because of the paucity of their own images and recollections. The words they possessed from their past were not enough. Some could see in it nothing more than a "gloomy wrinkle" in the face of the earth. Language stood in the way of preceiving it as anything more. Landscape stands created by language.

Mugerauer gives more examples of problems created by the inadequacy of our words, and then leaves us with the question: How can we improve description of milieu, how can we create an "environmental hermeneutics" (p. 67)? His answers are vague: (a) Seek to understand vernacular languages better, in their descriptions of local nature. What can be translated? What can be adapted to our forms of speech? (b) Penetrate the "ontology of the language event"-thus examine percisely what information the encounter with the environment provides. Both must be pursued in a historical, evolving context.

210 In this way this essay frames the problem for the entire book: In what way can we hope to understand the vernacular languages of things themselves in a clearer way? For we are at a juncture which Heidegger (1971) points out in The Thinker as Poet: "We are too late for the gods and too early for Being" (p. 4); it is too late for us to believe in divine word anymore. What then? The efforts of explanation in this book, however difficult they may seem at first, are to prepare us for a time when we can understand the world as it is. This is why the goal of "Being" often seems so much as a dream-it is so large and still so much beyond us. But we must try! It will not be easy. We don't even know how to express what is needed.

While pointing out the limitations of our traditional use of language, phenomenology advises us to let a person's own experiential descriptions and defining factors of their world lead to an "empathetic understanding" of other persons. This is the studying of another person's phenomenology, not some objective reality or general immersion in the landscape. There are many ways people perceive things differently. Geographer Miriam Helen Hill (in "Bound to the Environment: Towards a Phenomenology of Sightlessness") investigates the felt world of blind persons through their languages, their explanations of what they do. She concludes that the blind are by necessity far more sensitive to what is around them, far more immersed in their perceptions, and thus further along the road toward phenomenological understanding. The rest of us "must not let our 
eyes blind us to the world" (p. 109).

Anthropologists have often seemed blind to the actual behavior of foreign culture because they come to the field with such rigid preconceptions of how to study and work that they are blind to the alternative totality which a foreign cultures offers. Mugerauer quotes Levi-Strauss' autobiographical Tristes tropiques, which uses anthropological investigation cultures as a source of internal rapture rather than an effort to understand other ways of life. LeviStrauss seeks to become "a conneisuer of his own consciousness" (p. 65) rather than an intercultural communicator. Of course it is always impossible to know what an anthropologist has done with his data as we do not experience it directly. But architect David Saile's investigation of the Tewa Pueblo society ("Many Dwellings: Views of a Pueblo World") concentrates on what the people themselves have to say about their own pattern of places, instead of the application of outside theories for the purposes of schematic organization. A model from within the culture in question is worth 1,000 schema imposed from the outside.

Within anthropology, phenomenology seems to teach listening above all, and the concentrating on how to translate the unfamiliar accounts of the study population into a language that can reach a larger and different public. It seems that words cannot be avoided. We must turn to them in time, however much we become aware of their constrictions.

But the composer and philosopher of music Murray Schafer (in "Acoustic Space") leads us into the perceived world of pure sound, the soundscape, a phenomenon moving again beyond the eyes. "Speak that I may see you!" cries the Eskimo in the darker months, and this sounds odd to us only because we have largely forgotten how to listen. Schafer introduces the idea of "acoustic space" as a bridge between our culture and the unfamiliar. By its very universal presence, and prevalent ambiguity, our aural perception can touch boundaries and find ways to circumvent them.

But how can any of these nebulous understandings be taught? Architect Botond Bognar provides an example (in "A Phenomenological Approach to Architecture") from the architectural design studio where he teaches in Illinois: Students are asked to travel in an environment and then draw cognitive maps of what they remember of what they have experienced. Notes are compared - the experienced environments are found to be very different from one another, and quite different from any publishable plan or map. The built environment as experienced must be brought back into the teaching of architecture, says Bognar, to reduce alienation and revive a sense of what Christopher Alexander (1979) calls the "timeless way of building."

A guiding theme throughout the book is the search for authenticity, in identifying wholes and true symbols in nature, in learning how to 
dwell on earth in the spirit of Heidegger. This is an important aim if we are to recover any sort of lost identity in our frenzied but somehow barren times. But again I am not sure how much of phenomenology is authentically penetrable, especially to those of us uninitiated into its terminology. As any fixed language is an obstacle, so is phenomenological rhetoric also a block to our perception of its importance.

Architect Kimberley Dovey's essay, "The Quest for Authenticity and the Replication of Meaning," shows how our lack of authenticity manifests itself in a preponderance of "fake" recreations of nature: artificial beaches, nostalgic retirement communities with motor powered babbling brooks, wild game parks, and so forth. It is of course not a solution, but another symptom of a great sickness in our culture. They offer no answer; we still must create a viable and authentic way of living.

The quest for authenticity introduced here by Kimberley Dovey must also be applied to the field of philosophical inquiry. Authentic phenomenology should not direct one's attention too much in strange manners detached from usual context. For example, we should only concentrate heavily on the metaphor of the door (scc psychologist Richard Lang's contribution, "The Dwelling Door: Towards a Phenomenology of Transition") if we take time to remember what is on either side of it, as well of the question of why we

212 are on one side rather than the other. Efforts at phenomenology that forget this can seem all too far from real experience as it is lived by any of us-they can too quickly become a situation as artificial as the positivistic science which phenomenologists are constantly criticizing.

Not all phenomenology is authentic. A skeptical positivist might say that all of it is a form of fakery. One may need to look outside this book to find clues on how to judge the truthfulness of a phenomenological investigation. Different people may require different types of introduction. An excellent essay by one of the coeditors, geographer David Seamon (in press), mentions four criteria to help us perceive any rightness in phenomenological results: (a) Vividness-a quality which catches the reader, speaking of a genuine reality; (b) Accuracy-credibility, a quality that moves the reader beyond reading, resonating into our own lifeworlds; (c) Richness-refers to aesthetic fullness of the description. Is it complete enough to be taken seriously? and in contrast; (d) Elegance-economy and grace of description perhaps leaving enough space for us to insert our own details into it.

These criteria should be superimposed by readers on the topography of this book, as a legend to help us follow the cognitive maps which each contributor offers. The clearest aim of phenomenology, if there is something singular, is to encourage attentiveness to our world around us. "Perception is intentional," wrote Husserl, and we 
must work at it if we are to perceive more. On the other hand, phenomenology retains a certain mystic or religious bent, in any case something nonscientific. Forty years ago it was suggested that Merleau-Ponty ought to have been an artist of some kind. Should all these researchers give up any pretense of objectivity or generalization from their experiences and instead consider their efforts to be entirely creative writing?

Absolutely not! Science stands only to benefit from these bold attempts to try to understand things from their insides. Perhaps the word phenomenology does refer as much to an art as a science, in that it aims to present clear, creative, and individual descriptions as things that can resound with our own lives. Only it admits that this activity is more than the self-expression usually called art. But categories dissolve! The works collected in this volume are also a genuine contribution to the process of discovery and explanation that is the root of all science.

\section{References}

Alexander, C. (1979). The timeless way of building. Oxford: Oxford University Press.

Heidegger, M. (1971). The thinker as poet. Poetry, language, thought. New York: Harper \& Row.

Seamon, D. (in press). Phenomenology and environment-behavior research, advances in environment/behavior research. In G. Moore \& E. Zube (Eds.). New York: Plenum. 